\title{
Quality control study of hospital laundry in a tertiary care hospital
}

\author{
Kiran Gopal ${ }^{1}$, Solabannavar S.S. ${ }^{2}$ \\ ${ }^{1}$ Dr. Kiran Gopal, Assistant Professor, Department of Microbiology, Dr. Somervell Memorial CSI Medical College, Karakonam, \\ Thiruvananthapuram, Kerala, India. ${ }^{2}$ Dr. Shivakumar. S. Solabannavar, Professor \& Head, Department of Microbiology, \\ S. Nijalingappa Medical College and Hanagal Shri Kumareshwar Hospital and Research Centre, Bagalkot, Karnataka, India.
}

Corresponding Author: Dr. Shivakumar. S. Solabannavar, Professor \& Head, Department of Microbiology, S. Nijalingappa Medical College and Hanagal Shri Kumareshwar Hospital and Research Centre, Bagalkot, Karnataka, India. Email: dr.kgmicro@gmail.com.

\begin{abstract}
Introduction: Hospital laundry are potential reservoirs of bacteria in hospitals. Preventing contamination and providing clean linen and laundry should help to prevent hospital acquired infections. Being an important component in the management of patients and the role in causing hospital acquired infections, the study about hospital laundry has been undertaken in our hospital. Methods: Quality control practiced in the Linen and Laundry Service was studied by conducting a prospective study. Samples were taken from the surface of these materials by sweep plate method prior to washing procedure. The second set of samples were collected from the same materials after the washing procedure. The organisms were identified by colony morphology, culture characteristics \& biochemical reactions according to standard techniques. Results: Out of the 30 samples studied, 24 $(80 \%)$ of them were contaminated with bacteria before washing. Organisms yielded were Staphylococcus aureus, coagulase negative Staphylococcus (CONS), Aerobic spore bearing bacilli (ASB), Escherichia coli and Pseudomonas aeruginosa. After washing, 25 (83\%) of the clothes were sterile. Conclusion: Though terminal cleaning fails to completely eliminate bacteria from the laundered fabrics, it is effective in considerable reduction in bacterial growth.
\end{abstract}

Keywords: Quality control, Hospital laundry, Coagulase negative Staphylococcus

\section{Introduction}

Hospital laundry are potential reservoirs of bacteria in hospitals. Several studies have shown that the laundered clothes remain contaminated even after terminal cleaning [1]. The clean bedding and clean clothes install psychological confidence in the patients and the public.

Laundry in hospital arena includes:

- The clothing of patients, medical \& paramedical staffs.

- Clothing material used for patient care services in operation theatres, beds including mattresses, pillows, blankets, sheets, towels etc [1,2].

- Several studies have shown that the entire hospital room - especially hospital clothes remain contaminated even after terminal cleaning, that occurs after the patient is discharged [3].

- Increased risk of subsequent patient contracting diseases caused by these organisms.

- Recent studies have shown that if the previous occupant had infections with methicillin resistant Staphylococcus aureus (MRSA), vancomycin resistant Enterococci (VRE) or Clostridium difficile [4].

Manuscript received: $26^{\text {th }}$ October 2019

Reviewed: $5^{\text {th }}$ November 2019

Author Corrected: $10^{\text {th }}$ November 2019

Accepted for Publication: $15^{\text {th }}$ November 2019
- Increased risk of subsequent patient contracting diseases caused by these organisms.

- Among recent infections- significant increase in mortality due to Staphylococcus aureus - MRSA \& Clostridium difficile.

Significant number of deaths have also been attributed due to Escherichia coli \& other coliform organisms. Preventing contamination and providing clean linen and laundry should help to prevent hospital acquired infections.

Being an important component in the management of patients and the role in causing hospital acquired infections, the study about hospital laundry has been undertaken in our hospital.

\section{Objective}

- The study had two objectives:

- To identify the levels of bacterial contamination on laundry loads.

- To evaluate the efficiency of washing procedure. 


\section{Methods}

Study settings

- Department of Microbiology, S. Nijalingappa Medical College and Hanagal Shri kumareshwar Hospital and Research Centre, Bagalkot.

- Hospital laundry section, S. Nijalingappa Medical College and Hanagal Shri kumareshwar Hospital and Research Centre, Bagalkot.

Study design: Prospective study

Duration of Study: 6 months

Sampling method: Census method of sampling

Sample size: A total of 30 different launderable materials reaching hospital laundry section were selected for the study.

Inclusion criteria: Launderable materials reaching hospital laundry section - Bed sheets, Blankets, Surgeons suits, Surgeons gowns \& Pillow covers.

Exclusion criteria: Those samples of laundry, which do not come under the above-mentioned criteria.

Statistical analysis: Data obtained were consolidated, statistically evaluated using SPSS software version 16 and results obtained were represented using tables.

Methodology: The study was conducted after approval by the human ethics committee, S. Nijalingappa Medical College and Hanagal Shri Kumareshwar Hospital and Research Centre, Bagalkot.

Methods: Six samples each of bed sheets, blankets, pillow covers, Surgeon's suits \& Surgeon's gowns were studied.

- Samples were taken from the surface of these materials by sweep plate method prior to washing procedure.

- The second set of samples were collected from the same materials after the washing procedure.

- The samples are then transported to the microbiology laboratory.

- Processed for isolation of bacteria.

- The organisms were identified by colony morphology, culture characteristics \& biochemical reactions according to standard techniques [5].

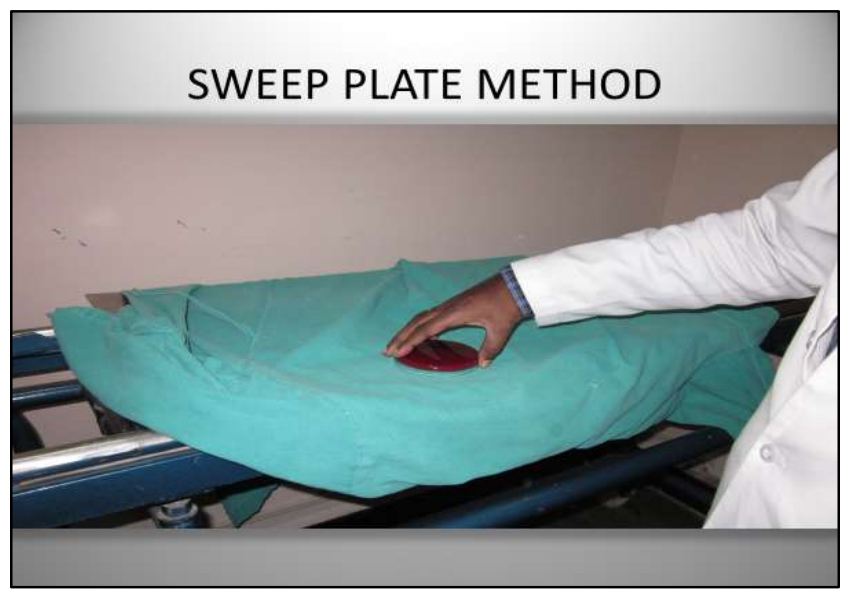

Fig-1: Sweep plate method.

\section{Results}

Out of the 30 samples studied, $24(80 \%)$ of them were contaminated with bacteria before washing. Out of which $23(76.67 \%)$ were positive for Gram positive cocci. Among these, 4 (17\%) were Staphylococcus aureus and 19 (83\%) were coagulase negative Staphylococcus (CONS), 14 (46.67\%) contained Aerobic spore bearing bacilli (ASB), 2 (6.67\%) Escherichia coli \& 1 (3.33\%) Pseudomonas aeruginosa (Table 1). 
Table-1: Analysis of samples before washing.

\begin{tabular}{|l|c|c|c|c|c|c|c|}
\hline & $\begin{array}{c}\text { Total } \\
\text { number }\end{array}$ & Sterile & CONS & S. aureus & P. aeruginosa & E. coli & ASB \\
\hline Sample & 30 & 6 & 19 & 4 & 0 & 2 & 14 \\
\hline Blanket & 6 & 0 & 4 & 2 & 1 & 0 & 4 \\
\hline Bed sheet & 6 & 0 & 5 & 1 & 0 & 2 & 4 \\
\hline Pillow cover & 6 & 1 & 5 & 1 & 0 & 0 & 3 \\
\hline Surgeon gown & 6 & 2 & 3 & 0 & 0 & 0 & 1 \\
\hline Surgeon suit & 6 & 3 & 2 & 0 & 0 & 0 & 2 \\
\hline
\end{tabular}

After washing, $25(83 \%)$ of the clothes were sterile; 5 clothes were still contaminated. Out of which, coagulase negative Staphylococcus (CONS) were isolated from 5 and Aerobic spore bearing bacilli ( $A S B)$ from 3 clothes after washing. No isolates of Escherichia coli or Pseudomonas aeruginosa were found after washing (Table 2).

Table-2: Analysis of samples after washing.

\begin{tabular}{|c|c|c|c|c|c|c|c|}
\hline & Total Number & sterile & CONS & S.aureus & P.aeruginosa & E.coli & ASB \\
\hline Sample & 30 & 25 & 5 & 0 & 0 & 0 & 3 \\
\hline Blanket & 6 & 4 & 2 & 0 & 0 & 0 & 1 \\
\hline Bed sheet & 6 & 5 & 1 & 0 & 0 & 0 & 1 \\
\hline Pillow cover & 6 & 5 & 1 & 0 & 0 & 0 & 1 \\
\hline Surgeon gown & 6 & 6 & 0 & 0 & 0 & 0 & 0 \\
\hline Surgeon suit & 6 & 5 & 1 & 0 & 0 & 0 & 0 \\
\hline
\end{tabular}

\section{Discussion}

In the present study, $83 \%$ of laundry yielded CONS before washing, which are consistent with a study done by Andrade et al [6]. Andrade et al also suggest that the usual disinfection procedures, instead of diminishing the number of microbes, merely displace them from one part to another, and the number of microorganisms remains the same. This finding was not present in the current study. In the present study, $10 \%$ of the total yielded organisms were Gramnegative bacilli (Escherichia coli \& Pseudomonas aeruginosa). After washing, $83 \%$ of the clothes were sterile.

Though the washing couldn't eliminate the entire microbes, most of pathogenic bacteria were killed after washing procedure. Bloomfield et al proved in his study that the origin of microbial contamination on textiles is closely linked to their use in different environments and includes dust, soil and food, which might even point to specific areas, e.g. healthcare facilities [7].

Blaser MJ et al showed in the study that a contamination with microorganisms resistant to desiccation (for example Staphylococcus aureus) as typical for this environment and assume that the amount of bioburden on laundry items like towels or sheets. The most common organisms isolated were Escherichia coli and Pseudomonas aeruginosa among gram negative bacilli and Staphylococcus species among gram positive organisms. This is very well correlating with the present study. They concluded that low-temperature washing is as effective as high-temperature washing for eliminating pathogenic bacteria from hospital laundry [8].

Most species identified from the samples correspond to usual members of skin microflora or bacteria from the environment. Studies done by E. A. Hooker et al and R. R. Banville showed Gram-positive cocci were the most prevalent organisms. These findings are coherent with the present study $[9,10]$.

Biofilms could be a potential reservoir for pathogens and might detach during the washing process and recontaminate the laundry. In this regard it can be assumed that the washing process may cause a shift in the microbial community on textiles form primary contaminants (skin bacteria) to secondary contaminants (biofilm-associated environmental bacteria) and that the water itself can also be a source for recontamination and contribute to secondary contamination [11].

Munk et al and Kubota et al postulated that the formation of smelly substances on washed textiles is caused by bacterial metabolization of sweat residues, for example by Moraxella species $[12,13]$. 
A. Pinon et al did a study on hospital clothing and reported that only eight samples contained S. aureus (two clean bed items, three dirty bed sheets, three uniforms), and a single dirty bed sheet was contaminated with a non-pathogenic Enterococcus strain. However, a majority of isolated species may act as opportunistic pathogens, given the fragility and possibly weakened immune system of patients staying in a hospital.

This finding is correlating with the present study. Microbial species were mostly bacteria commonly found in the environment or on human skin, such as staphylococci or micrococci. Nevertheless, $57 \%$ of the identified species may be opportunistic pathogens for humans, representing a risk for people with a deficient or weakened immune system, especially in cases of superinfection.

Since contamination of linen seems to occur after washing, actively antimicrobial textiles would represent a valuable measure to prevent textiles from being a vehicle for transfer of microorganisms [14].

Limitations of the present study: The results and interpretation could not be reviewed and discussed in detail because only very few studies have been done in the topic. Bacterial isolates were not tested for antimicrobial susceptibility, since our final objective was to assess the efficacy of washing procedure.

\section{Conclusion}

A good hospital laundry section is one of the quality indicators in the patient care. Hospital laundry is a potential reservoir to harbour bacteria and transmitting the infection. Adequate cleaning practices will completely eliminate the route of transmission of infection through laundry. Terminal cleaning can considerably reduce the bacterial growth from the laundered fabrics. It's very important to note that most of the pathogenic bacteria are killed during washing.

\section{What the study adds to the existing knowledge?}

If the clothes are not washed properly, hospital laundry can be a source of disease transmission. A good washing can significantly reduce the microbial load, hence reduce hospital acquired infections.

\section{Author's contribution}

Dr. Kiran Gopal: Design of study protocol, proper methodology, collection of data \& manuscript.

Dr. Shivakumar S Solabannavar: Guided the research work \& manuscript editing.
Funding: No funding sources

Conflict of interest: None declared

Ethical Approval: This study was approved by the Institutional Ethics Committee

\section{References}

1. Singh D, Qadri GJ, Kotwal M, Syed AT, Jan F. Quality Control in Linen and Laundry Service at A Tertiary Care Teaching Hospital in India. Int J Health Sci. Qassim Uni 2009;3(1):33-44.

2. Hooker EA, Allen S, Gray L and Kaufman C. A randomized trial to evaluate a launderable bed protection system for hospital beds. Antimicrob Resist Infect Cont. 2012;1(1):27. doi: 10.1186/2047-2994-1-27.

3. Christian RR, Manchester JT, Mellor MT. Bacteriological quality of fabrics washed at lower than standard temperatures in a hospital laundry facility. Appl Environ Microbiol. 1983;45(2):591-597.

4. Reid T, Wilson AW, Galloway DB. A Comparative Study on the Disinfection of Hospital Laundry Using Ozone: A 2-part Single Blind Study Using Standard Hospital Laundry Cleaning Techniques versus the OTEX Validated Ozone Disinfection System. Final Study Report, Protocol No. Ozone/01-2007/120207/Hospital Laundry Study, Version. 2007; 6:22.

5. Colle JG, Marmion BP, Fraser AG, Simmons A. Mackie \& McCartney Practical Medical Microbiology. $14^{\text {th }}$ ed. Elsevier; London:1996.

6. Andrade DD, Angermani ELS, Padovani CR. A bacteriological study of hospital beds before and after disinfection with phenolic disinfectant. Pan Am J Public Health.2000;7(3):179-184. doi: 10.1590/s1020-498920000 -00300007 .

7. Bloomfield SF, Exner M, Signorelli C, Nath KJ, Scott EA. The infection risks associated with clothing and household linens in home and everyday life settings, and the role of laundry. Int Sci Forum Home Hyg. 2011:1-43.

8. Blaser MJ, Smith PF, Cody HJ, Wang WLL, LaForce FM. Killing of fabric-associated bacteria in hospital laundry by low temperature washing. J Infect Dis. 1984;149(1):4857. doi: 10.1093/infdis/149.1.48.

9 Hooker EA, Allen S, Gray L, Kaufman C. A randomized trial to evaluate a launderable bed protection system for hospital beds. Antimicrob Resist Infect Cont. 2012;1(1):27. doi: http://dx.doi.org/10.1186/2047-2994-1-27. 
10. Banville RR, McNeil E. Microbiology of Dry cleaning. App Microbiol. 1966; 14(1):1-7.

11. Bockmuehl DP. Laundry hygiene how to get more than clean. J Appl Microbiol. 2017;122(5):1124-1133. doi: 10.1111/jam.13402.

12. Munk S, Johansen C, Stahnke LH, Adler-Nissen J. Microbial survival and odor in laundry. J Surfactants Deterg. 2001;4(4):385-394. doi: 10.1007/s11743-0010192-2.
13. Kubota H, Mitani A, Niwano Y, Takeuchi K, Tanaka A, Yamaguchi $\mathrm{N}$, et al. Moraxella species are primarily responsible for generating malodor in laundry. Appl Environ Microbiol. 2012;78(9):3317-3324. doi: 10.1128/ AEM.07816-11.

14. Pinon A, Gachet J, Alexandre V, Decherf S, Vialette M. Microbiological Contamination of Bed Linen and Staff Uniforms in a Hospital. Advan Microbiol. 2013;3(7):515519. doi: 10.4236/aim.2013.37069.

\section{How to cite this article?}

Kiran Gopal, Solabannavar S.S. Quality control study of hospital laundry in a tertiary care hospital. Trop J Path Micro 2019;5(12): 983-987.doi:10.17511/ jopm.2019.112.03 